\title{
Matrix Regenerating Agent (RGTA) in a Neurotrophic Corneal Ulcer
}

\author{
Sara Pereira ${ }^{1}$, Rui Resende ${ }^{1}$, Pedro Coelho ${ }^{1}$, Filipa Sampaio ${ }^{1}$ \\ 1. Ophthalmology, Hospital Pedro Hispano, Porto, PRT
}

Corresponding author: Sara Pereira, salves_gp@hotmail.com

\begin{abstract}
Neurotrophic keratopathy is a condition associated with corneal damage and impaired corneal healing. There are no specific treatments available for this disease and current treatments are not associated with improved visual function. Matrix regenerating agents (RGTA) are recent topical agents showing positive results in the treatment of several corneal conditions, including neurotrophic keratopathy.

We report the case of a 73-year-old patient with a neurotrophic ulcer treated with RGTA.

Treatment with RGTA allowed complete corneal healing and a dramatic recovery in visual function in our patient. RGTA solutions are an important and safe therapeutic option for the treatment of selected corneal pathology.
\end{abstract}

Categories: Ophthalmology

Keywords: neurotrophic ulcer, matrix regenerating agent, cornea

\section{Introduction}

Neurotrophic keratopathy is a rare degenerative corneal disease caused by trigeminal damage. This condition is characterized by a decrease in corneal sensitivity and impaired corneal healing. Currently, there are no specific medical treatment and management depends on the severity and stage of the disease. Some surgical approaches are useful in preserving eye integrity, however, these treatments do not show a significant impact on visual function [1].

Matrix regenerating agents (RGTA) are recent topical agents that show encouraging results in promoting tissue healing and regeneration, including cases of neurotrophic ulcers, corneal dystrophies or postsurgical conditions $[2,3]$.

Review began 10/08/2020 Review ended 10/18/2020 Published 10/26/2020

(c) Copyright 2020

Pereira et al. This is an open access article distributed under the terms of the Creative Commons Attribution License CC-BY 4.0., which permits unrestricted use, distribution, and reproduction in any medium, provided the original author and source are credited.

\section{Case Presentation}

A 73-year-old female patient presented to the emergency department complaining of ocular pain and decreased visual acuity on her right eye for about three weeks. Her medical records showed left eye amaurosis and arterial hypertension. On examination, she presented best corrected visual acuity of hand movements in the right eye, marked conjunctival injection and an extensive corneal ulcer occupying the inferior half of the eye (Figure 1). 


\section{Cureus}

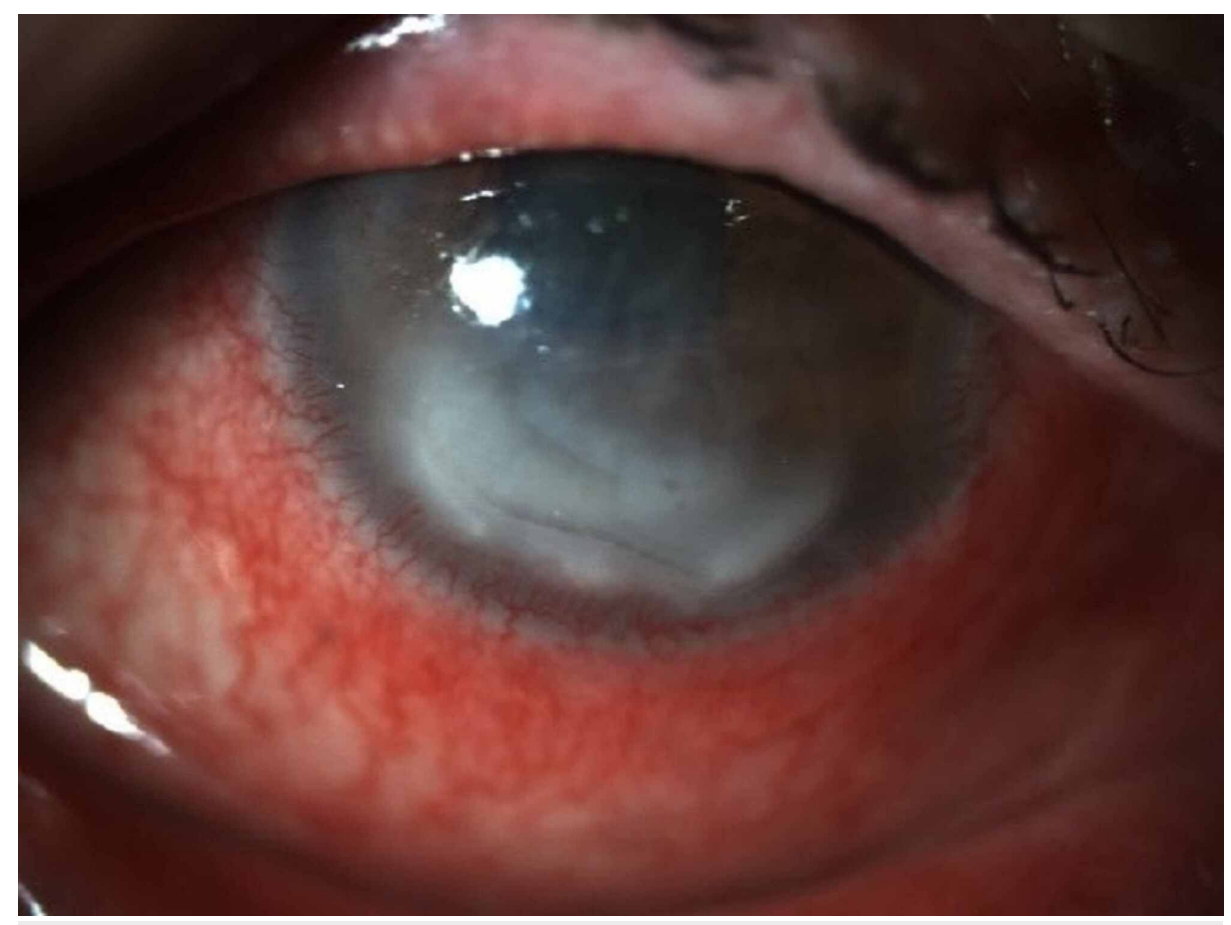

\section{FIGURE 1: Corneal ulcer before treatment}

The patient was started on topical broad-spectrum antibiotics, without significant improvement after one week of treatment. Microbiological and virologic analysis were negative (Figure 2).

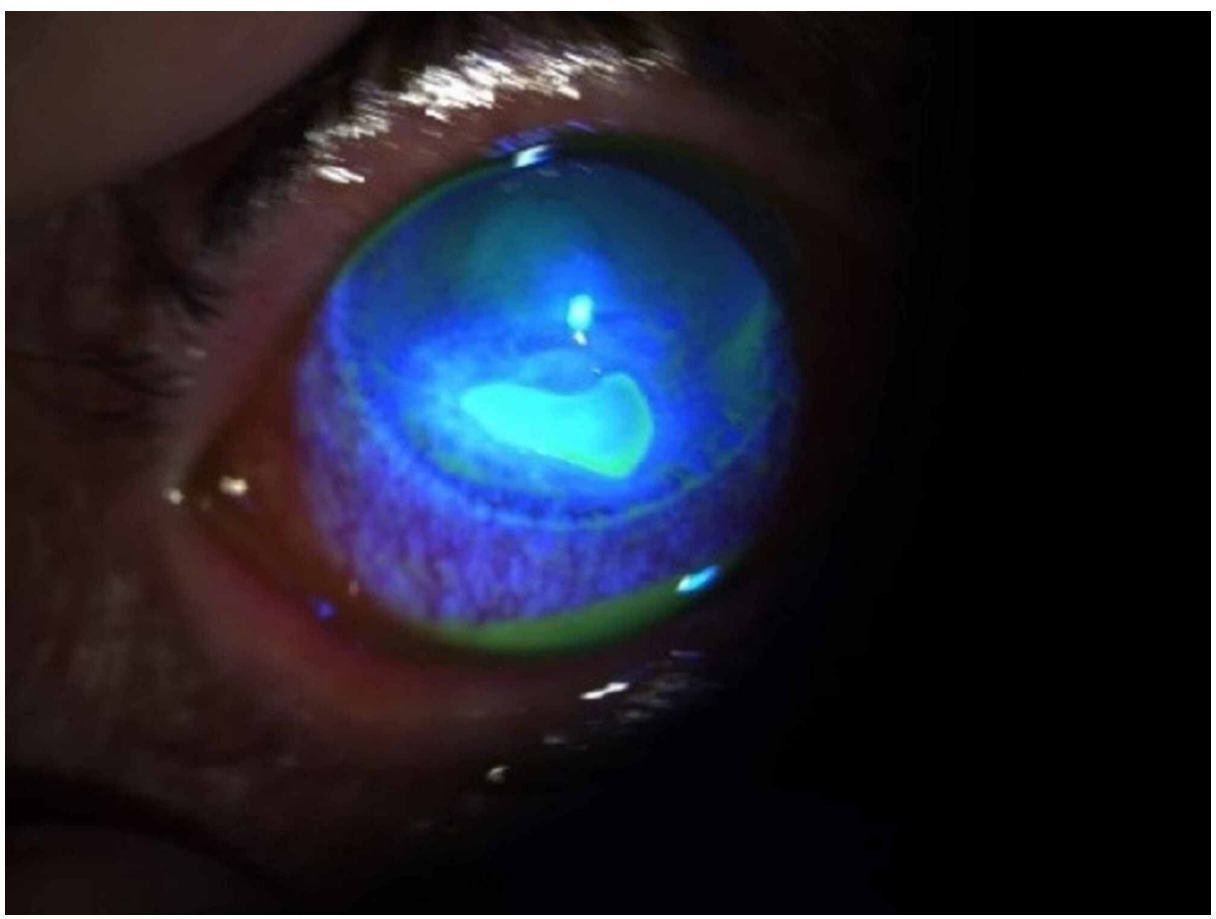

FIGURE 2: Corneal ulcer one week after treatment with antibiotics

Given the possibility of a neurotrophic ulcer, the patient started application of RGTA eye drops - Cacicol ${ }^{\circledR}$, one drop every 48 hours. After 10 applications of RGTA - Cacicol ${ }^{\circledR}$, the patient showed complete ulcer healing with a significant decrease in ocular pain and surface inflammation and a marked improvement in best corrected visual acuity of 4/10 (Figures 3,4 ). 


\section{Cureus}

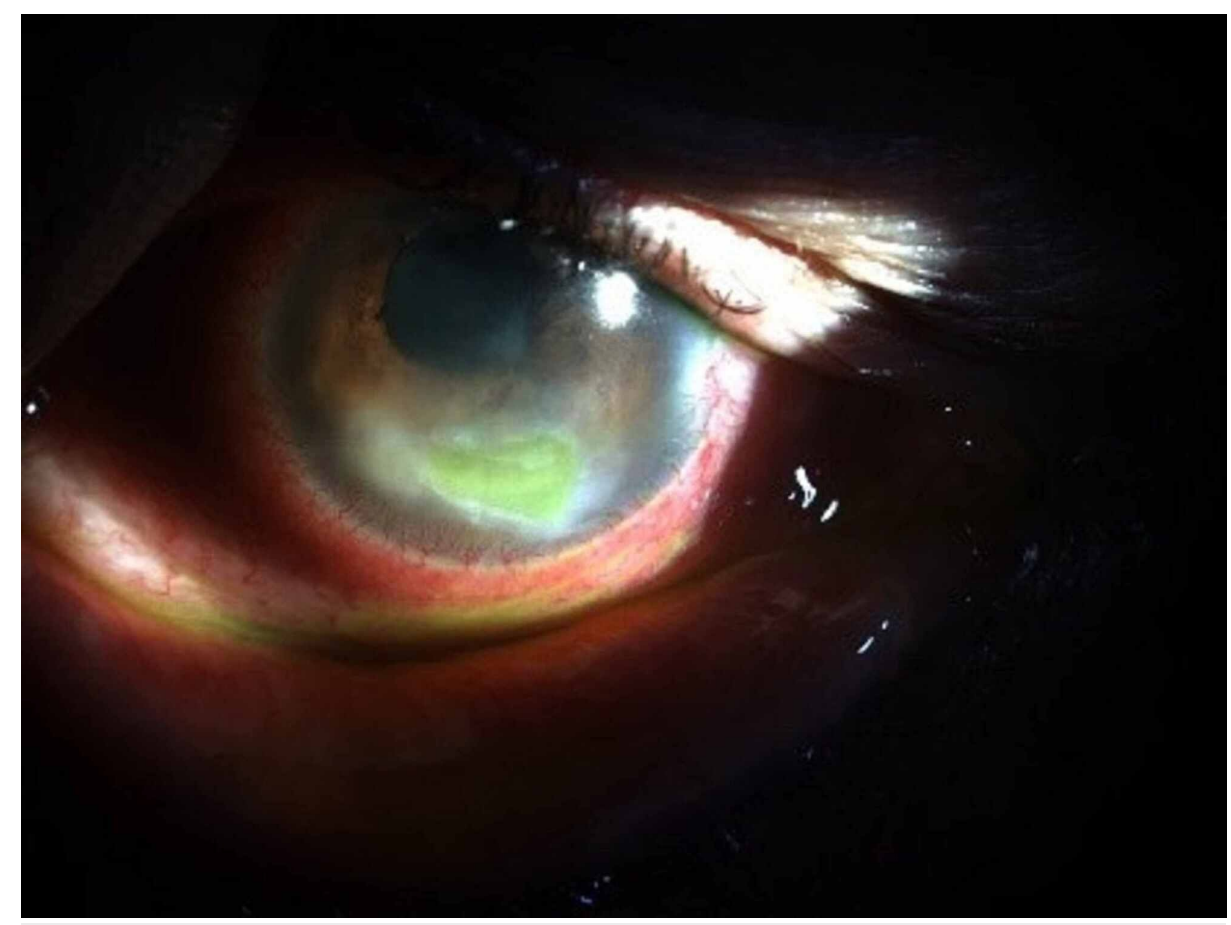

FIGURE 3: Corneal ulcer after three applications of RGTA

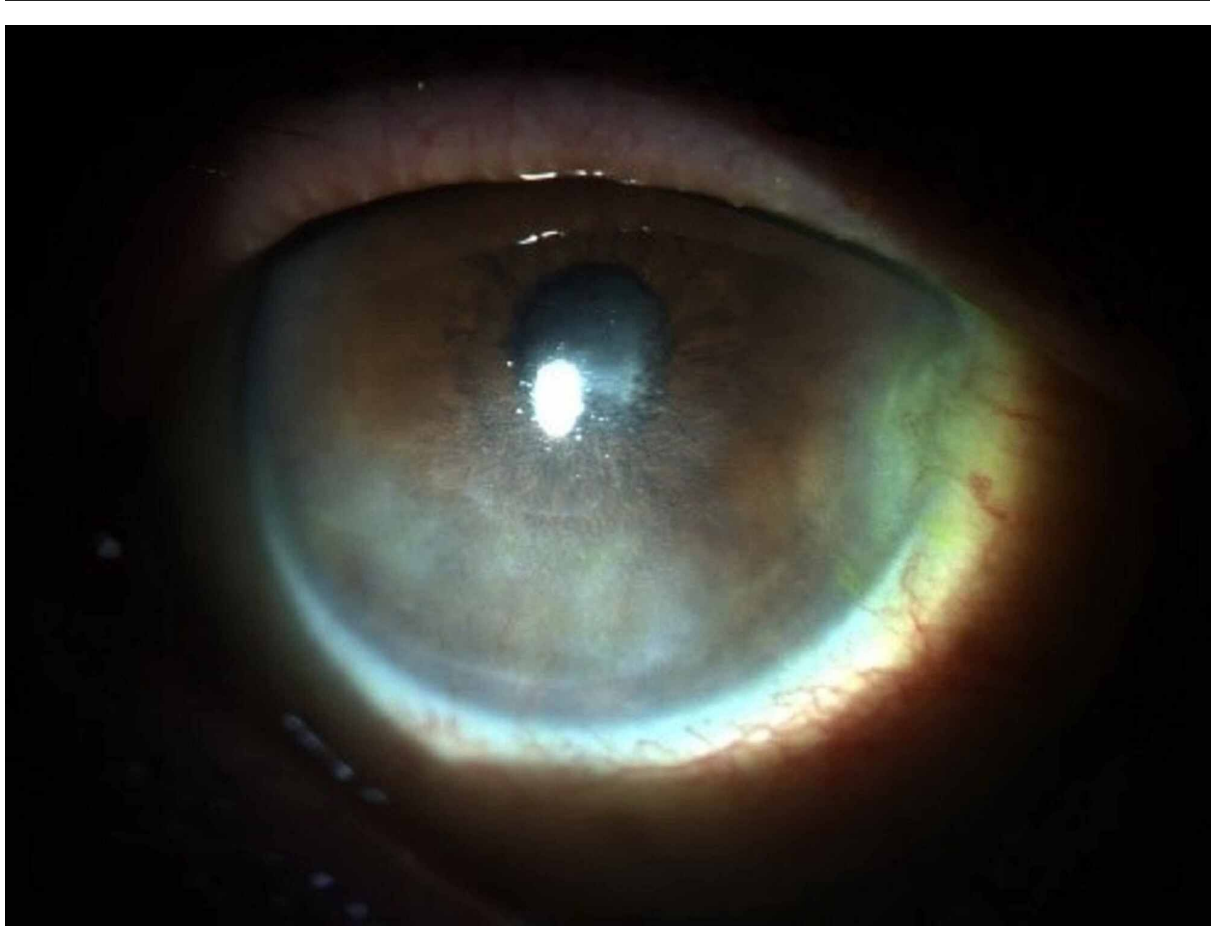

FIGURE 4: Corneal ulcer after 10 applications of RGTA

\section{Discussion}

Neurotrophic keratopathy is a rare entity characterized by impairment of corneal trigeminal innervation and development of corneal recurrent epithelial defects and ulceration. This disease can be potentially sightthreatening [1]. A neurotrophic ulcer is a diagnosis of exclusion and its treatment is a clinical challenge, with a specific treatment lacking.

Several management strategies are used for late stage neurotrophic ulcers, such as use of therapeutic contact lenses, amniotic membrane transplantation or surgical tarsorrhaphy and conjunctival flap. These 
Regenerating matrix agent (RGTA), mimicking heparan sulfate, promotes regeneration of damaged tissues and enhances tissue healing. Several studies have demonstrated the efficacy of these agents on corneal healing, including not only neurotrophic ulcers, but also in re-epithelialization after penetrating keratoplasty and chronic corneal dystrophies [2-7]. This topical and preservative-free agent is very welltolerated with the benefits of having a very simple application regimen and the potential to decrease possible surgical interventions.

The utility of RGTA agents is not limited to the ophthalmological field, with evidence of efficacy in the treatment of a wide spectrum of conditions, such as chronic skin and diabetic ulcers, oral and gastrointestinal tract associated lesions and tendon and muscle regeneration [8]. Its efficacy in wound healing and reducing fibrosis has made it useful in reconstructive surgical procedures and postoperative care [9].

In our case, the patient showed complete corneal reepithelialization with a profound recovery of visual acuity in a monocular patient with only three weeks of treatment. There was no treatment-related local or systemic side effects and the patient did not report pain or discomfort during application.

\section{Conclusions}

Treatment with RGTA showed significant enhancement of corneal reepithelialization and a complete resolution of ocular inflammation.

RGTA ophthalmic solutions are an important and safe therapeutic option for controlling ocular surface inflammation and promoting corneal healing.

\section{Additional Information \\ Disclosures}

Human subjects: Consent was obtained by all participants in this study. Conflicts of interest: In compliance with the ICMJE uniform disclosure form, all authors declare the following: Payment/services info: All authors have declared that no financial support was received from any organization for the submitted work. Financial relationships: All authors have declared that they have no financial relationships at present or within the previous three years with any organizations that might have an interest in the submitted work. Other relationships: All authors have declared that there are no other relationships or activities that could appear to have influenced the submitted work.

\section{References}

1. Sacchetti M, Lambiase A: Diagnosis and management of neurotrophic keratitis. Clin Ophthalmol. 2014, 8:571-579. 10.2147/OPTH.S45921

2. Brignole-Baudouin F, Warnet JM, Barritault D, Baudouin C: RGTA-based matrix therapy in severe experimental corneal lesions: safety and efficacy studies. J Fr Ophtalmol. 2013, 36:740-747. 10.1016/j.jfo.2013.01.012

3. Guerra M, Marques S, Gil JQ, et al.: Neurotrophic keratopathy: therapeutic approach using a novel matrix regenerating agent. J Ocul Pharmacol Ther. 2017, 33:662-669. 10.1089/jop.2017.0010

4. Aifa A, Gueudry J, Portmann A, Delcampe A, Muraine M: Topical treatment with a new matrix therapy agent (RGTA) for the treatment of corneal neurotrophic ulcers. Invest Ophthalmol Vis Sci. 2012, 53:8181-8185. 10.1167/iovs.12-10476

5. Chappelet MA, Bernheim D, Chiquet C, Aptel F: Effect of a new matrix therapy agent in persistent epithelial defects after bacterial keratitis treated with topical fortified antibiotics. Cornea. 2017, 36:1061-1068. 10.1097/ICO.0000000000001261

6. Jullienne R, Garcin T, Crouzet E, He Z, Renault D, Thuret G, Gain P: Evaluation of corneal epithelial wound healing after penetrating keratoplasty in patients receiving a new matrix therapy agent (regenerating agent). Eur J Ophthalmol. 2020, 30:119-124. 10.1177/1120672118808971

7. Chebbi CK, Kichenin K, Amar N, Nourry H, Warnet JM, Barritault D, Baudouin C: Pilot study of a new matrix therapy agent (RGTA OTR4120) in treatment-resistant corneal ulcers and corneal dystrophy (Article in French). J Fr Ophtalmol. 2008, 31:465-471. 10.1016/s0181-5512(08)72462-8

8. Barritault D, Gilbert-Sirieix M, Rice KL, et al.: RGTA $^{\circledR}$ or ReGeneraTing Agents mimic heparan sulfate in regenerative medicine: from concept to curing patients. Glycoconj J. 2017, 34:325-338. 10.1007/s10719-0169744-5

9. Zakine G, Le Louarn C: First applications of matrix therapy in plastic and aesthetic surgery (Article in French). Ann Chir Plast Esthet. 2010, 55:421-428. 10.1016/j.anplas.2010.07.011 